\title{
Contesting the $\pi$ value
}

\section{Morina $\mathrm{E}^{\star}$}

Independent Researcher, Leonrodstr 72, 80636 Munich, Germany

\begin{abstract}
This paper addresses several topics in mathematics and in particular it aims to answer the following questions: Why is it that the $\pi$ value cannot be $\pi=3.1415$. Why should this value be different? Where can one notice the wrong calculations and its effects? Based on the results obtained, we conclude that the value 3.1415 is a value that does not respond to reality and does not give correct results. The reasons for this conclusion are mentioned several times and appropriate arguments are presented. For the sake of truth this value should be different, and at the same time should no longer continue to be used. Contradictions in the 3.1415 value first began in the Geomechanical laboratory during calculations where this value always provided wrong results. In direct analysis where cutting cohesion and tangent are required, the surface of the sample which enters the apparatus for analysis is of the size $d=71 \mathrm{~mm} \mathrm{r}=35.5 \mathrm{~mm}$. When this area is estimated according the principles of Archimedes a smaller surface is obtained, the result is $39.57 \mathrm{~cm}^{2}$ and when this area is calculated according to the 3.24 value then we obtain an area of $40.83 \mathrm{~cm}^{2}$ which is represented as $39.57 \mathrm{~cm}^{2}$ therefore cohesion and tangent are erroneous results in this analysis. The next error is the analysis of suppression (compression). Where the frame of the apparatus have the measure of sample size $d=71 \mathrm{~mm}, r=35.5 \mathrm{~mm}$ which is compressed and one can later discover the degree of sample deformation. The mistake lies in that the real sample in the framework of the apparatus is $40.83 \mathrm{~cm}^{2}$, while we calculate the value of the surface as $39.57 \mathrm{~cm}^{2}$. Review of soil analysis is also mistaken. When the sample with the size $\varnothing 50 \mathrm{~mm}$ and length $100 \mathrm{~mm}$ is subject to the vertical force until it breaks, the resulting resisting force does not belong to the sample that lies in the frame of the apparatus.
\end{abstract}

Keywords: $\pi$ Value; Force; Cirlce; Chord; Perimeter

\section{Introduction}

This study will present a number of analysis, calculations and contradictions which you have not encountered in literature until now.

\section{The Circle}

Any closed curve with a centera center that hast he same distance from all points in the perimeter, is called a circle. Consequently, the circle is a closed curve that creates $360^{\circ}[1,2]$.

- $\quad$ Diameter (d)

- $\operatorname{Radius~(r)~}$

- Chord

- $\operatorname{Perimeter}(\mathrm{P})$.

The diameter $(\mathrm{d})$ - is the straight line that unites two points of perimeter passing through the center of the circle. The diameter determines the size of a circle. Radius ( $r$ ) the diameter represents half of the circle. A straight line from the center which touches a point oft he perimeter. Chord is a segment that unites two points oft he perimeter without passing through the center [1-10].

The perimeter of a circle - is the length of a circle. a closed circle which has $360^{\circ}$. Any theory which defines the perimeter of a circle which is not closed and does not form $360^{\circ}$ that theory is wrong. The perimeter of a circle is a wrong definition which is inherited from the past. This error produces many other erros.

\section{The $P$ Number $(\pi)$}

The number $\mathrm{P}(\pi)$ is also knows as the Archimede's constant. $\pi$ is an irrational number. $\pi$ is defined as the quotient of the perimeter of a circle with ist diameter. This result in subsequem with the conclusion that the perimeter of the circlr itself ist he number $P(\pi)$. Pi can not be written as a fraction. This number is also known as the Rudolf's number. There are many mathematicians who have worked on this theory, with a special focus on increasing decimals. However in the end the value remains 3.1415 with is regarded as crucial in calculations in many domains to this day [1-10].

\section{The goal of the study}

Today, modern science knows very different types of measurements which ate utilized to address different needs. Examples include the measurement of length. Volume, energy, fat, etc. All these measures have their own specificities. Of course they have standards and norms of their own. This scientific paper will present an error, which brings with it many other errors. This error belongs to Archimedes, who when rotating a circle in a horizontal plane calculates the length of circle that passes with a millimeter scale. This is nothing but a mistake of that era.

\section{Why is it wrong?}

The error is evident because: the circular shape of the body itself determines the measurement of that body, how and with what measuring scale it is to be read. If the body in a circle, which in the case of Archimedes has $360^{\circ}, \mathrm{d}=100 \mathrm{~mm} \mathrm{r}=50 \mathrm{~mm}$. is rotated in a horizontal plane its length will be $314.15 \mathrm{~mm}$. The circle at the same time will complete two scales: the scale that shows the calculation of degrees and angles as well as the millimeter scale that is obtained by rotating the circle in the horizontal plane. The change is major, to illustrate with

*Corresponding author: Morina E, Independent Researcher, Leonrodstr 72 80636 Munich, Germany, Tel: 017681339513; E-mail: ekrem_morina@web.de

Received August 03, 2017; Accepted October 02, 2017; Published October 05 2017

Citation: Morina E (2017) Contesting the $\pi$ value. J Phys Math 8: 249. doi 10.4172/2090-0902.1000249

Copyright: (C) 2017 Morina E. This is an open-access article distributed under the terms of the Creative Commons Attribution License, which permits unrestricted use, distribution, and reproduction in any medium, provided the original author and source are credited. 
a $8.722 \mathrm{~mm}$ length we obtain (pass through) $10^{\circ}$ of the circle. It was already mentioned that the circle has $360^{\circ}$. When the whole circle rotates the length of $314.15 \mathrm{~mm}$ is obtained according to Archimedes. This value is obtained by not taking into account the angles that the curve forms- the curve called a circle passes through angles without taking account of them. The real circle does not exist, otherwise we say that the circle is an infinite polygon. By passing these angles are, without calculating them. We obtain the wrong result where we consider the perimeter of the circle to be $314.15 \mathrm{~mm}$ resulted in Figure 1.

Application details: Take a circular plaque of $\mathrm{X}$ mm thickness with a diameter $\mathrm{d}=100 \mathrm{~mm}$. If this circular plate is rotated in a horizontal plane and we measure the length it will be $314.15 \mathrm{~mm}$. If this plaque is wrapped with a wire with a thickness of $1 \mathrm{~mm}$ ad with a length of $314.15 \mathrm{~mm}$ we will see that this length does not close the circle of $360^{\circ}$. A wire of $1.0 \mathrm{~mm}$ thickness which reels the plaque with $\mathrm{d}=100 \mathrm{~mm}$. once laid in a horizontal plane its length will reach $324 \mathrm{~mm}$. The value 3.1415 gives erroneous results in the calculation of surface area of the circle as well as in calculating angles. volume etc. Therefore we can conclude that where the value 3.1415 is used, the results are wrong. This will be illustrated in the examples to follow.

\section{Calculating the Perimeter}

It was already mentioned that the perimeter is a closed curve with a center of $360^{\circ}$. The formulas for the calculation of the perimeter of a circle are the following $[1,2]$

$$
\begin{aligned}
& \mathrm{P}=2 \cdot 3.24 \bullet \mathrm{r} \\
& \mathrm{d}=2 \cdot \mathrm{r} \\
& d=\frac{P}{3,24}=\frac{324 \mathrm{~mm}}{3,24}=100 \mathrm{~mm}
\end{aligned}
$$

The perimeter of the circle can also be calculated with the following formula:

$$
\begin{aligned}
& \mathrm{P}=4 \pi \cdot \mathrm{r}^{2} 4 \cdot 3.24=12.96 \\
& \mathrm{r}^{2}=2500 \\
& \mathrm{P}=12.96 \cdot 2500=32400 \mathrm{~mm}
\end{aligned}
$$

The length of a circle's arc is also calculated with the following formula:

$$
\mathbf{b}=\frac{2 \cdot r \cdot \pi \cdot a}{360} \Rightarrow>\frac{100 \cdot 3.24 \cdot 10}{360}=\frac{3240}{360}=9 \mathrm{~mm}
$$

According to Archimedes this result is (Figure 2):

$$
\mathrm{b}=\frac{100 \cdot 3.1415 \cdot 10}{360}=\frac{3141,5}{360}=8,7263888 \mathrm{~mm}[1-10] \text {. }
$$

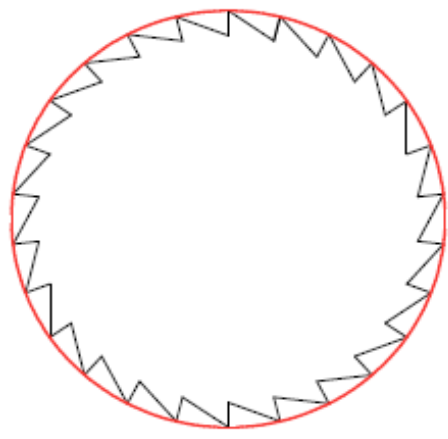

Figure 1: An example to illustrate the concept of pi.
Example: A square with the size of $100 \mathrm{~cm}^{2}$ in it we place a circle with the size $\mathrm{d}=100 \mathrm{~mm}$.

Question: What ist he difference between the perimeter oft he square and the perimeter oft he circle which is given as Figure 3.

The perimeter of the circle is $324 \mathrm{~mm}$,

The perimeter of the square $400 \mathrm{~mm}$,

The difference is $76 \mathrm{~mm}$,

In every angle oft he square we have a $19 \mathrm{~mm}$ difference.

$100 \mathrm{~mm} \bullet 4=400 \mathrm{~mm}$,

$81 \mathrm{~mm} \bullet 4=324 \mathrm{~mm}$,

$19 \mathrm{~mm} \cdot 4=76 \mathrm{~mm}$.

When we calculate according tot he formula: $\alpha=360 \cdot \frac{b}{d \cdot 3,24}$ we will obtain:

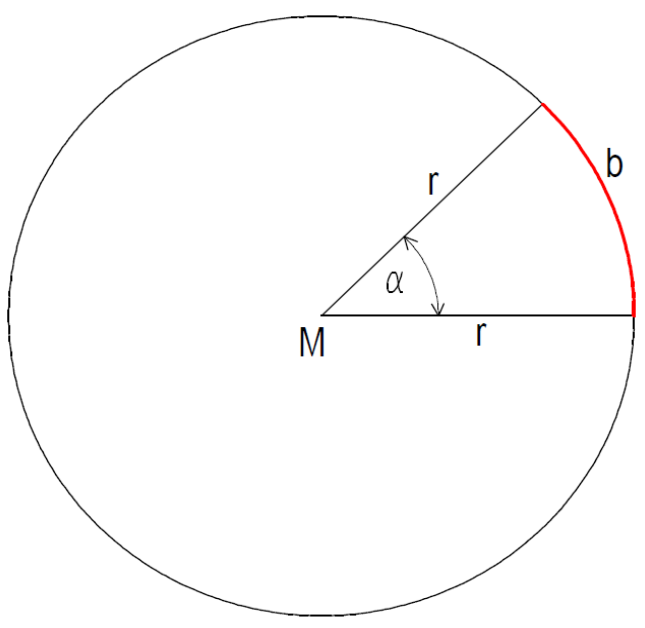

Figure 2: Calculating the value of a circle's arc.

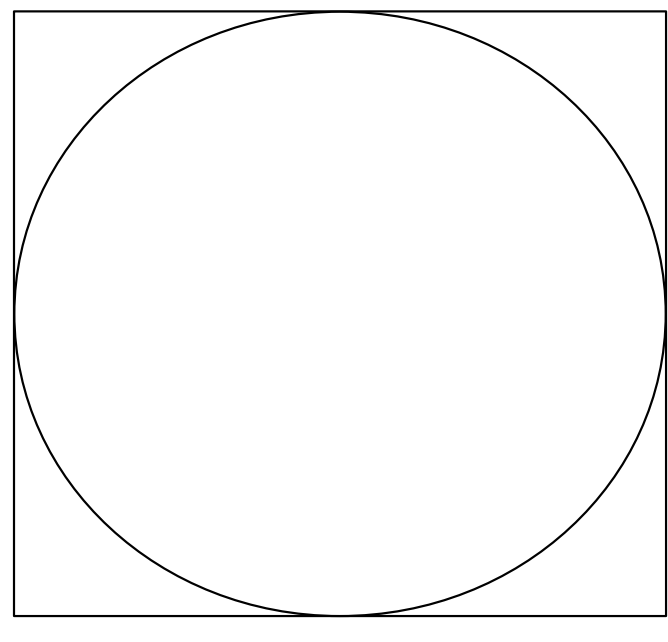

$100 \mathrm{~mm}$

Figure 3: The square with the size $100 \mathrm{~cm}^{2}$ and circle with a radius of $r=50$ $\mathrm{mm}[1,2]$. 
$360 \cdot \frac{400 \mathrm{~mm}}{324}=444,444444^{\circ}$

For the $76 \mathrm{~mm}$ length we will obtain

$$
\begin{aligned}
& 360 \cdot \frac{76 \mathrm{~mm}}{324}=84,4444444^{\circ} \\
& 444.4444444^{\circ}-84.4444444^{\circ}=360^{\circ}
\end{aligned}
$$

The length oft he perimeter is calculated with the following formula:

$P=2 \pi \cdot r \cdot \frac{\alpha}{360^{\circ}}=>6,28 \cdot 50 \cdot 1 / 360=0,8729$

The new value: $6,48 \cdot 50 \mathrm{~mm} \cdot \frac{1^{\circ}}{360^{\circ}}=0.9 \mathrm{~mm}$

$6,48 \cdot 50 \mathrm{~mm} \cdot \frac{90^{\circ}}{360^{\circ}}=81 \mathrm{~mm}$

$6,48 \cdot 50 \mathrm{~mm} \cdot \frac{180^{\circ}}{360^{\circ}}=162 \mathrm{~mm}$

$6,48 \cdot 50 \mathrm{~mm} \cdot \frac{270^{\circ}}{360^{\circ}}=243 \mathrm{~mm}$

$6,48 \cdot 50 \mathrm{~mm} \cdot \frac{360^{\circ}}{360^{\circ}}=324 \mathrm{~mm}$

Accroding to Archimede's results the value of 6.28 is also known as $2 \pi$. If we break these values down we will abtain the following:

$$
\begin{aligned}
& 6,28 \cdot 50 \mathrm{~mm} \cdot \frac{90^{\circ}}{348,8888889^{\circ}}=81 \mathrm{~mm} \\
& 6,28 \cdot 50 \mathrm{~mm} \cdot \frac{270^{\circ}}{348,8888889^{\circ}}=243 \mathrm{~mm} \\
& 6,28 \cdot 50 \mathrm{~mm} \cdot \frac{270^{\circ}}{348,8888889^{\circ}}=243 \mathrm{~mm} \\
& 6,28 \cdot 50 \mathrm{~mm} \cdot \frac{360^{\circ}}{348,8888889^{\circ}}=324 \mathrm{~mm}
\end{aligned}
$$

When the values deviate we will obtain the following results:

$$
\begin{aligned}
& 6,28 \cdot 50 \mathrm{~mm} \cdot \frac{1^{\circ}}{360^{\circ}}=0,87222 . \mathrm{mm} \\
& 6,28 \cdot 50 \mathrm{~mm} \cdot \frac{360^{\circ}}{360^{\circ}}=3.14 \mathrm{~mm}
\end{aligned}
$$

\section{The calculation oft he perimeter with the help of a hexagon}

By employing hexagons we are able to calculate the perimeter of a circle. We place one hexagon inside the circle, and another one in the surface outside the circle as shown in Figure 4

$58 \mathrm{~mm}+29 \mathrm{~mm}=87 \mathrm{~mm}$ ose $\frac{87 \mathrm{~mm}}{2}=43,5 \mathrm{~mm}$ ose $29 \mathrm{~mm}+25$ $\mathrm{mm}=54 \mathrm{~mm}$

$50 \mathrm{~mm}+25 \mathrm{~mm}=75 \mathrm{~mm} \frac{75 \mathrm{~mm}}{2}=37,5 \mathrm{~mm} \frac{54 \mathrm{~mm}}{2}=27 \mathrm{~mm}$

$87 \mathrm{~mm}+75 \mathrm{~mm}=162 \mathrm{~mm} 43.5 \mathrm{~mm}+37.5 \mathrm{~mm}=81.00 \mathrm{~mm} 58 \mathrm{~mm}$ $+50 \mathrm{~mm}=108 \mathrm{~m}$

$$
\frac{162 \mathrm{~mm}}{2}=81 \mathrm{~mm} \frac{108 \mathrm{~mm}}{2}=54 \mathrm{~mm}
$$

$54 \mathrm{~mm}+27 \mathrm{~mm}=81 \mathrm{~mm}$

\section{Calculating the Surface of the Circle}

The calculation of the surface of the circle in this paper will take up most space. The surface of a circle has been the cause of all this work and study. It is precisely the surface of the circle which mostly

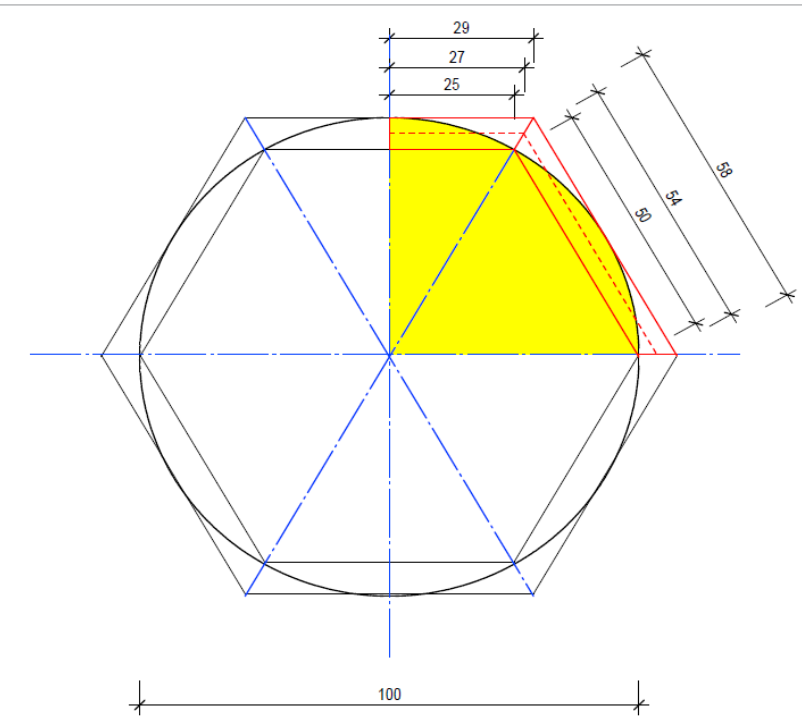

Figure 4: Te hexagon inside the circle and the hexagon outside the circle.

experiences the consequences of wrong results resulting from the value 3.1415. By calculating the wrong surface value we will undoubtedly have wrong results during analysis in different domains. Concrete cases will be mentioned at the end of this paper. Next we will discuss the result of the surface of a circle with a diameter $\mathrm{d}=100 \mathrm{~mm}$ and $360^{\circ}$. Present research will use formulas that are still valid today in order to conduct the necessary calculations [11].

$$
S=r^{2} \cdot \pi=\frac{d^{2}}{4}
$$

If we break down this formula we will notice that the result will be incorrect. The formual which will provide the correct result is the following:

$$
\begin{aligned}
& S=r^{2} \cdot 3,24=d^{2} \cdot \frac{3,24}{4}=81,00 \mathrm{~cm}^{2} \\
& \mathrm{~S}=3.24 \cdot \mathrm{r}^{2} \\
& S=3,24 \cdot=\frac{d^{2}}{4} \\
& \mathrm{r}^{2}=2500 \\
& S=\frac{P^{2}}{\pi 4}=>S=\frac{104967}{12,96}=81,00 \mathrm{~cm}^{2}
\end{aligned}
$$

Where: $324^{2}=10496$

$$
4 \cdot 3.24=12.96
$$

The surface can also be calculated with the following formula (Figure 5):

$\mathrm{S}=0.5 \cdot \mathrm{a} \cdot \mathrm{h}$

$\mathrm{a}=40.5 \mathrm{~mm} \mathrm{~h}=50.00 \mathrm{~mm}$

$\mathrm{S}=0.5 \cdot 40.5 \mathrm{~mm} \cdot 50 \mathrm{~mm}=1012.5 \mathrm{~mm}^{2}$

$1012.5 \cdot 8=8100 \mathrm{~mm}^{2}$ ose $81.00 \mathrm{~cm}^{2}$.

Consider a circle with $\mathrm{d}=100 \mathrm{~mm}$. is divided in eight equal parts (Figure 6):

$40.5 \mathrm{~mm} \bullet 8=324 \mathrm{~mm}$

$40.0 \mathrm{~mm} \bullet 8=320 \mathrm{~mm}$. 


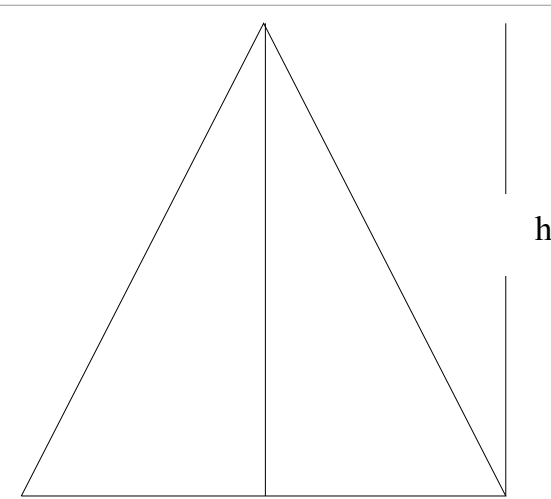

Figure 5: One eighth of the circle (1/8).

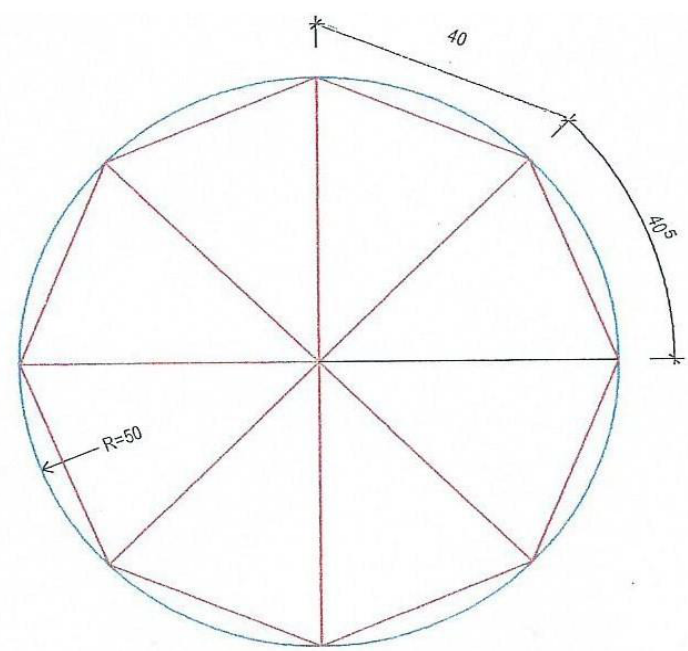

Figure 6: The circle with $\mathrm{r}=50 \mathrm{~mm}$ is divided in eight angles.

$$
\begin{aligned}
& \text { The difference is } 4 \mathrm{~mm} \quad 1^{\circ} \cdot \frac{320 \mathrm{~mm}}{0,9}=355,5555556^{\circ} \text {. } \\
& 1^{\circ} \cdot \frac{4 \mathrm{~mm}}{0,9}=4,4444444^{\circ} \\
& 355.5555556^{\circ}+4.4444444^{\circ}=360^{\circ}
\end{aligned}
$$

Calculate the surface of the circle in Figure 7. Where $\mathrm{d}=100 \mathrm{~mm}$. $\mathrm{P}=314.15 \mathrm{~mm}$.

$\mathrm{S}=10000 * \frac{314.15}{4}=7853 \mathrm{~mm}^{2}$ ose

$\mathrm{S}=0.5 \cdot 314.15 \mathrm{~mm} \cdot 50=7853 \mathrm{~mm}^{2}$.

$\mathrm{S}=78.53 \mathrm{~cm}^{2}$.

The surface of the cirlcel is represented in Figure 8.

\section{Calculating the circle's surface value with three methods}

The surface of the circle can be represented in three ways also means that the surface can be calculated with three different methods (Figure 9):

Where: $\mathrm{d}=100 \mathrm{~mm} \mathrm{r}=50 \mathrm{~mm}$

- The shape of the circle

- The shape of the triangle

- The shape of the rectangle.

The calculation in a circular form: $S=10000 \cdot \frac{3,24}{4}=81,00 \mathrm{~cm}^{2}$.

The calculation in the triangular form: $\mathrm{S}=0.5 \cdot 324 \mathrm{~mm} \cdot 50$ $\mathrm{mm}=81.00 \mathrm{~cm}^{2}$.

The calculation in a rectangular form: $\mathrm{S}=162 \mathrm{~mm} \cdot 50 \mathrm{~mm}=81.00$ $\mathrm{cm}^{2}$.

$81 \mathrm{~mm} \cdot 50 \mathrm{~mm}=4050 \mathrm{~mm}^{2} 72^{\circ}+18^{\circ}=90^{\circ}$.

$4050 \mathrm{~mm}^{2} \cdot 2=8100 \mathrm{~mm}^{2} 90^{\circ} \cdot 4=360^{\circ}$.

Or $81 \mathrm{~cm}^{2}$.
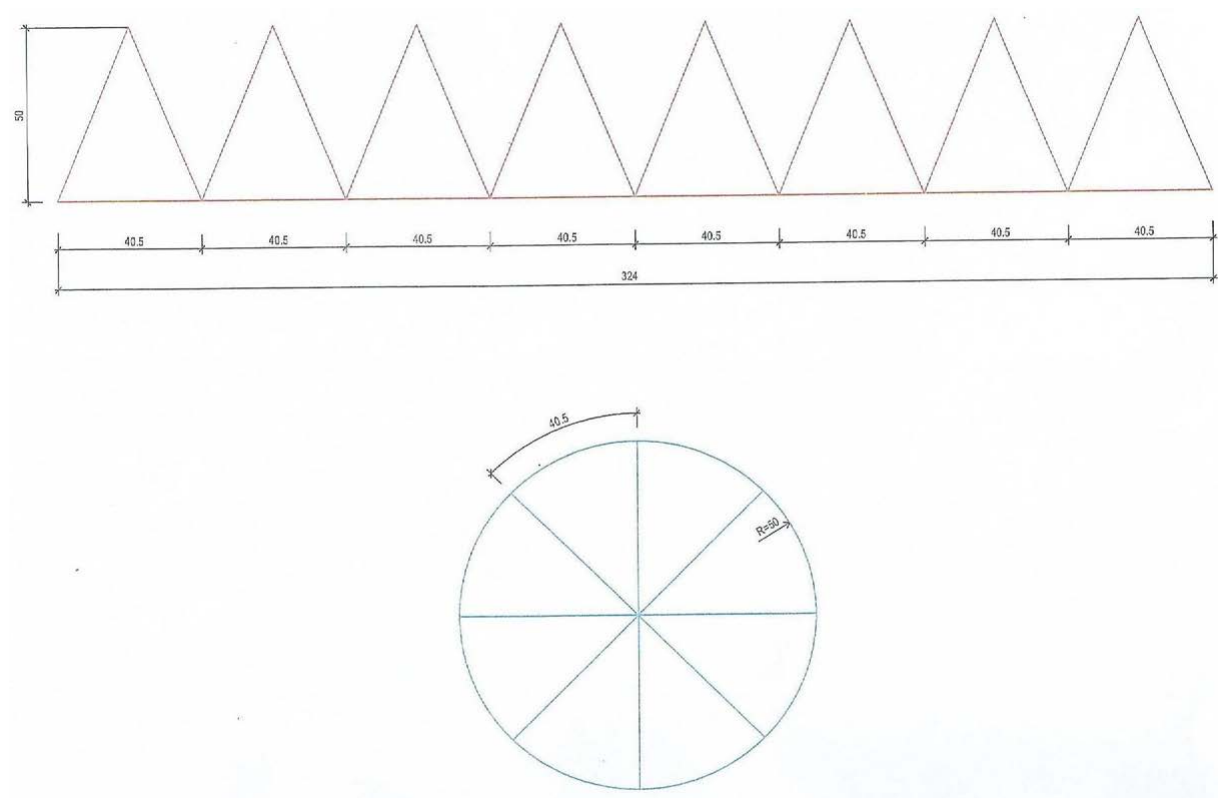

Figure 7: Representing the surface of the circle in a horizontal plane. 


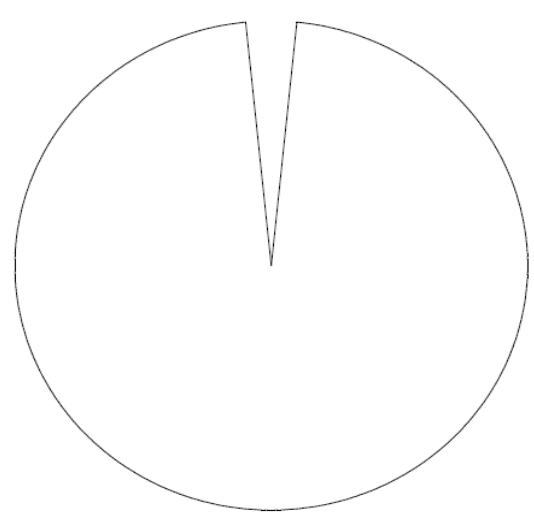

Figure 8: The circle with a radius value of $r=50 \mathrm{~mm}$, the length of the perimeter $314,15 \mathrm{~mm}$.

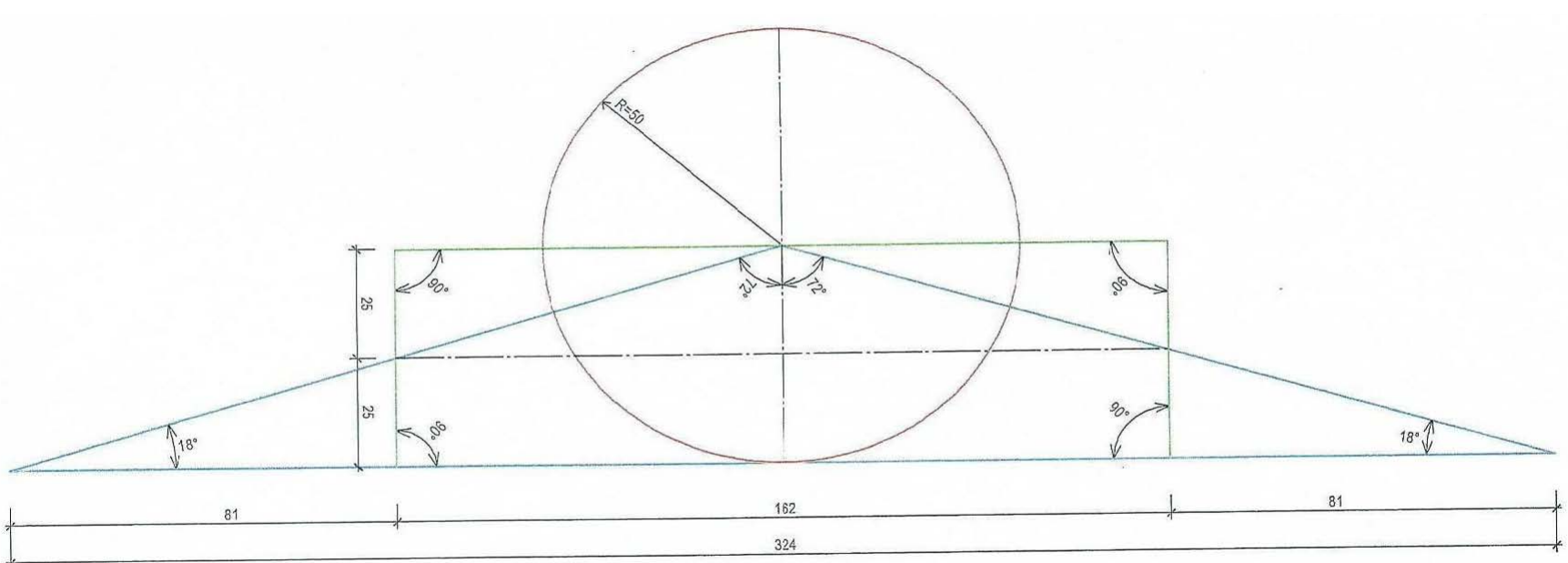

Figure 9: The surface of the circle in three methods.

Calulate the surface of the semi circle in three different methods (Figures 10 and 11):

Where: $\mathrm{d}=100 \mathrm{~mm}$

The calculation: $S=0.5 \cdot 162 \mathrm{~mm} \cdot 50 \mathrm{~mm}=40.50 \mathrm{~cm}^{2}$

$\mathrm{S}=10000 * \frac{162 \mathrm{~mm}}{4}=40.50 \mathrm{~cm}^{2}$

$\mathrm{S}=81 \mathrm{~mm} \cdot 50 \mathrm{~mm}=40.50 \mathrm{~cm}^{2}$.

\section{The calculation of the surface with the help of a hexagon}

Calculating the Vale of the one fourth of the circle's surface.

$2025.00 \mathrm{~mm}^{2} \bullet 4=8100 \mathrm{~mm}^{2}$.

$\mathrm{S}=81.00 \mathrm{~cm}^{2}$.

\section{Calculating the surface of the circle with the help of water}

Based on the theory that $1 \mathrm{~cm}^{3}$ is equal to $1 \mathrm{~mL}$. Then the calculation of the surface withh the aid of water is done in the following way:

Instructions - A container made of $\mathrm{d}=100 \mathrm{~mm}$ and with $\mathrm{h}=100 \mathrm{~mm}$.

If calculated according tot he value 3.1415 the end of this container is $78.53 \mathrm{~cm}^{2}$.

When the container with these dimensions is filled with water then the water level $785 \mathrm{ml}$ should reach $\mathrm{h}=100 \mathrm{~mm}$. When thew water level reaches does not reach the height $100 \mathrm{~mm}$ then we conclude that the calculation oft he end surface oft he vessel is not correct. The end of the container surface does not amount to a value of $78.53 \mathrm{~cm}^{2}$. Figure 12 provides illustrations of two containers where thei surface is calculated with the value 3.1415 and the value of 3.24 illustarted in Figure 12A and 12B. If a vessel with $\mathrm{r}=50 \mathrm{~mm} \mathrm{~h}=200 \mathrm{~mm}$ is filled with water $785.3 \mathrm{ml}$ • $2=1570.6 \mathrm{ml}$ the water will clearly not reach the level. $\mathrm{h}=200 \mathrm{~mm}$. This means that once we calculate the value 3.1415 the surface of the vessel is reduced. If the surface of the veesel is calculated with the value 3.24 the surface is calculated at $81 \mathrm{~cm}^{2}$ and the water in the vale of $810 \cdot 2=1620$ $\mathrm{ml}$ will reach the level $\mathrm{h}=200 \mathrm{~mm}$. From this result we can conclude: 1 $\mathrm{cm}^{3}$ is equal to $1 \mathrm{ml}$ water or $1 \mathrm{dm}^{3}=1 \mathrm{~L} \mathrm{H}_{2} \mathrm{O} .1 \mathrm{~L}=1000 \mathrm{ml} \mathrm{H}_{2} \mathrm{O}=1000$ $\mathrm{cm}^{3}$ (Figure 13A and 13B).

In the Figure 13A the surface of the vessel is calculated with the value 3.1415. While in the Figure 13B the surface of the veesel is calculated with the value 3.24 .

\section{Density}

Density is defined as the amount of mass within a volume [11]

Density=mass $/$ Volume

$D=\frac{m}{V}\left(\mathrm{~kg} / \mathrm{m}^{3}\right)$ or $\left(\mathrm{g} / \mathrm{cm}^{3}\right)$. 


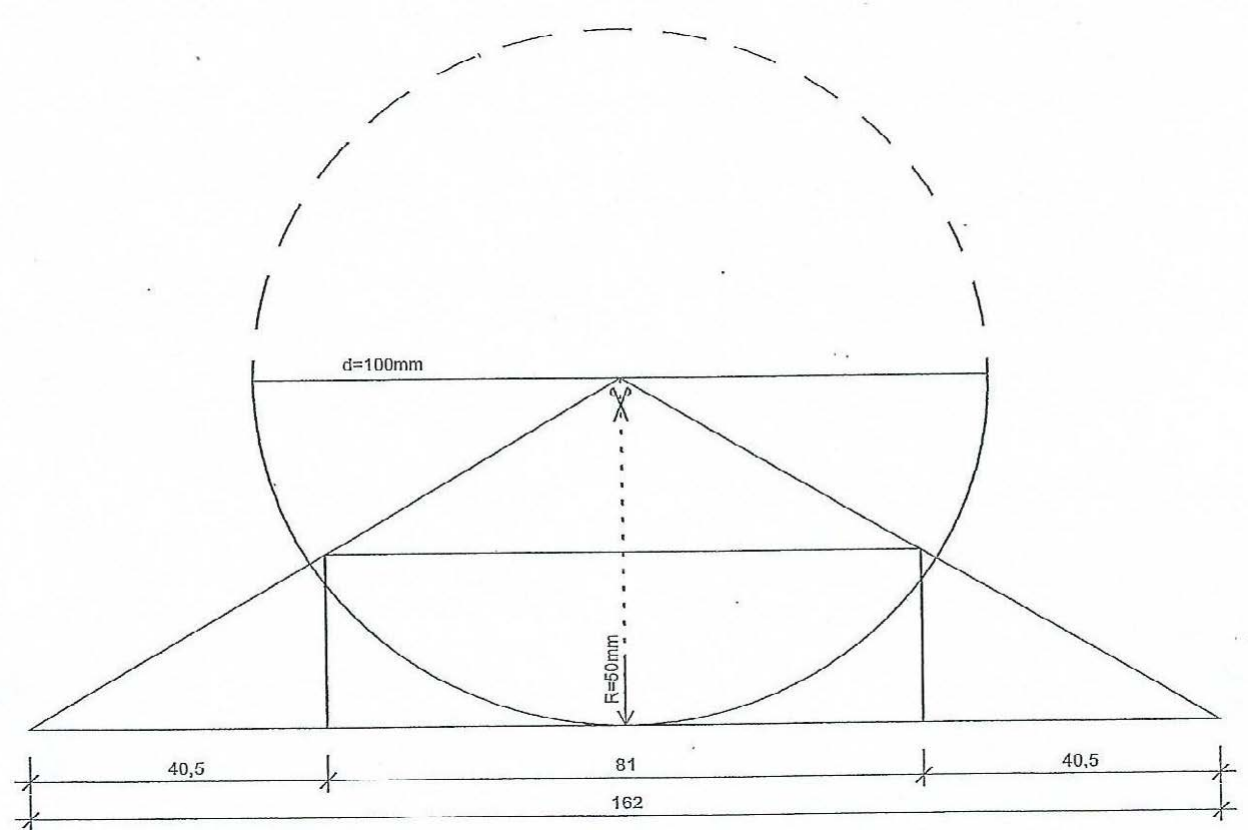

Figure 10: The surface of the circle in three forms.

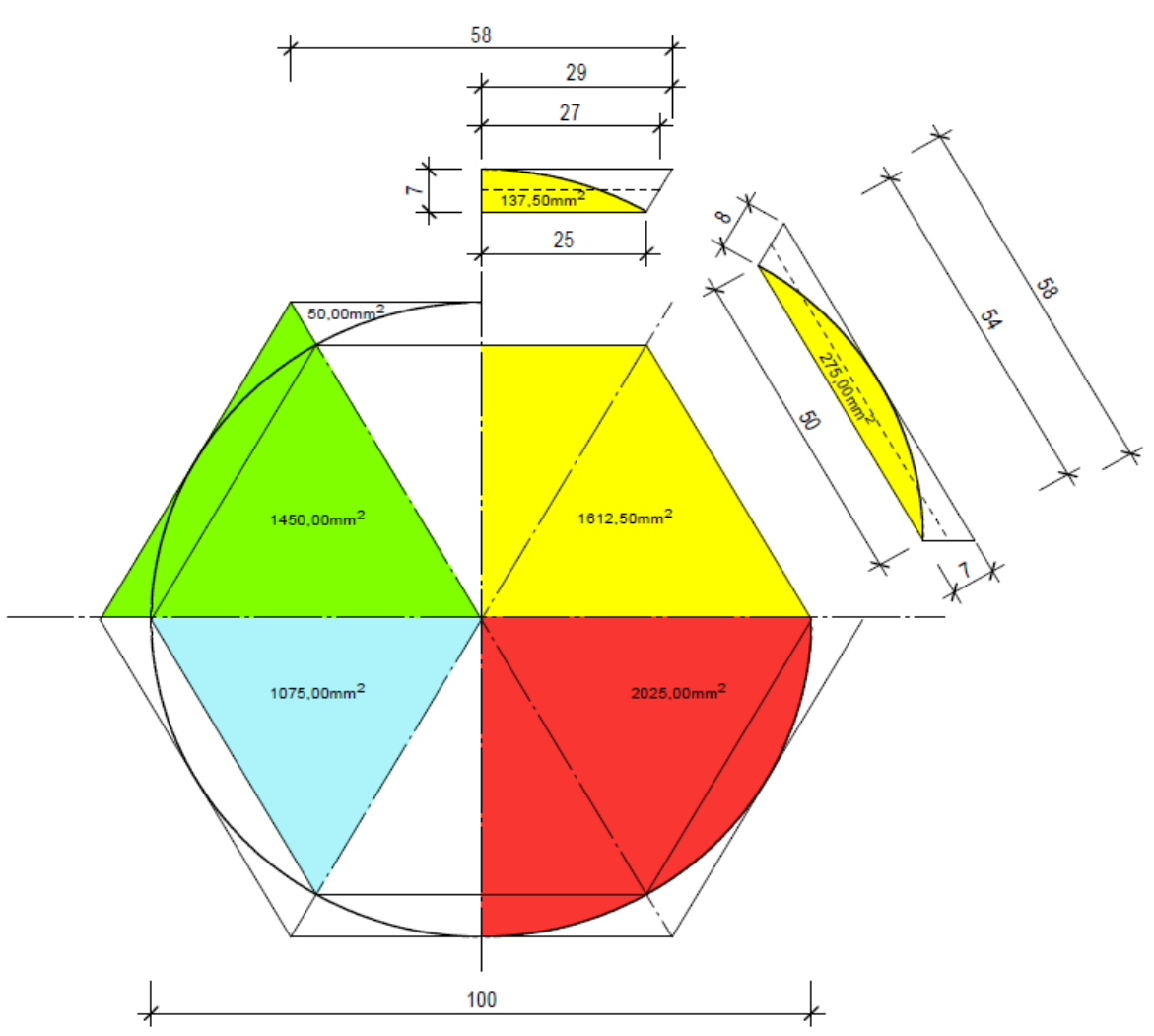

Figure 11: Calculating the Vale of the one fourth of the circle's surface.

This definition this formula is valid and today takes its rightful place in contemporary science. In 1964 based on this formula it was established that the volume in a 1 liter water in temperature $+4^{\circ} \mathrm{C}$ in normal pressure is equal to $1 \mathrm{~m}^{3}=1000 \mathrm{dm}^{3} 1 \mathrm{dm}^{3}=1000 \mathrm{~mL}$ or $(1 \mathrm{~L}) 1$ $\mathrm{mL}=1 \mathrm{~cm}^{3}$.
By breaking down the density formula for mass and volume as well as by calculating with the formula $\mathrm{V}=\mathrm{r}^{2} \boldsymbol{\bullet} \pi \mathrm{h}$ it can be confirmed that the value $\pi=3.1415$ is not real, is not accurate and always provides incorrect results. In the following calculations and figures it will be proven that the 3.1415 value deviates the results obtained once. 

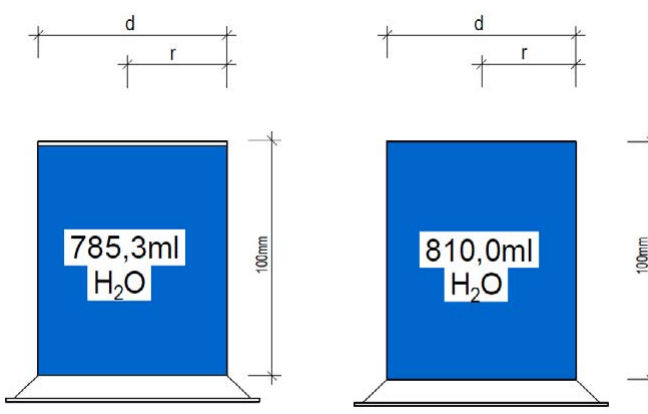

Figure 12: $(A$ and $B) A$ plastic container was used in this illustration, which was in accordance with the specified dimensions.
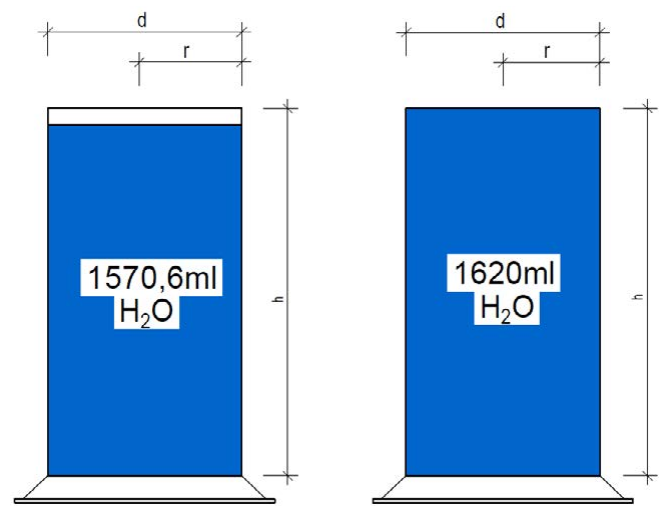

Figure 13: (A) The surface of the vessel is calculated with the value 3,1415 . (B) While the surface of the vessel is calculated with the value 3,24 .

A cylinder - tube with $\mathrm{d}=60 \mathrm{~mm} \mathrm{~V}=1000 \mathrm{ml}$ we measure the weight which in our case is $804.80 \mathrm{~g}$. This tube needs to be filled with $600 \mathrm{~mL}$ of distilled water. One must wait a few minutes and read the water level in the tube. We define point A. Once point A is carefully defined which in our case is $500 \mathrm{~cm}^{3}$ is placed inside the tube the water level will rise and we will obtain point $B$. the rise from point $A$ to point $B$ is $170 \mathrm{~mm}$. In our case is necessary to know the increase in the level when the mass is $1000 \mathrm{~cm}^{3}$.

$170 \mathrm{~mm} \cdot 2=340 \mathrm{~mm}$.

The height of level in the beaker in the value of $\mathrm{h}=340 \mathrm{~mm}$ is filled with water and the same mass is weight in a digital scale. The weight of the water will be equal to the volume of the mass $1000 \mathrm{~cm}^{3}$ a volume that is 991.440 . From this the level $\mathrm{H}$ is obtained which is necessary to calculate the volume.

Calculations where: $\mathrm{h}=340 \mathrm{~mm} \mathrm{r}=30 \mathrm{~mm} \pi=3.1415$

Formula: $\mathrm{V}=\mathrm{r}^{2} \cdot \pi \cdot \mathrm{h} \mathrm{V}=900 \cdot 3.1415 \cdot 340 \mathrm{~mm}=961.299 \mathrm{~mL}$.

This result does not provide the volume of $1000 \mathrm{~cm}^{3}$, the volume which is defined in the beaker in which the calculation and the experiment was conducted. While the above mentioned values are calculated according to the value of 3.24 we will obtain the following results:

$\mathrm{r}=30 \mathrm{~mm} ; 3.24 \mathrm{~h}=340 \mathrm{~mm}$

$\mathrm{V}=900 \cdot 3.24 \cdot 340 \mathrm{~mm}=991.440 \mathrm{~mL}$.

By comparing the results obtained we conclude that the value obtained is equal to the volume level as defined in the beaker $1000 \mathrm{~cm}^{3}$.
By comparing the two calculations above we understand that the value $\pi=3.1415$ during calculations tends to deviate the volume of the mass in the case represented in Figure 14. While in the second calculation the result is in accordance with the volume of the mass as defined in the baker [11].

Volume of the mass $(\mathrm{Vm}) \mathrm{Vm}=\mathrm{a} \cdot \mathrm{b} \cdot \mathrm{c} \mathrm{Vm}=40 \mathrm{~mm} \bullet 40 \mathrm{~mm}$ • $312.5 \mathrm{~mm}=500 \mathrm{~cm}^{3}$.

The diameter of the beaker is $\mathrm{d}=60 \mathrm{~mm} \mathrm{r}=30 \mathrm{~mm}$.

The change in water levels from point $A$ to point $B$ is: $A-B=170$ $\mathrm{mm}$.

$170 \mathrm{~mm} \cdot 2=340 \mathrm{~mm} \mathrm{~h}=340 \mathrm{~mm}$.

Today the science calculates the volume through the following formulas:

$\mathrm{V}=\mathrm{r}^{2} \bullet \pi \cdot \mathrm{h}$ si dhe $\mathrm{Vm}=\mathrm{a} \bullet \mathrm{b} \bullet \mathrm{c}$. When the calculation is completed with identical values then the result ought to be the same. However, in reality the value 3.1415 results in a deviation in the outcome of the calculation. Nevertheless, the scientists maintain that the results are identical and we accept a mistake of the past.

\section{Gravity}

The force acting on any body in the area of the extraterrestrial bodies. A force that is directed at the center of the celestial body its base. With the help of gravity this paper will prove that the value $\pi=3.1415$ is a value that deviates results in practical work. The results obtained during calculations of gravity will be the one that will correct and prevents diversions.

Instructions: The aerometer is placed inside a beaker with the size of $500 \mathrm{~mL}$. We will begin to fill the beaker with distilled water until the

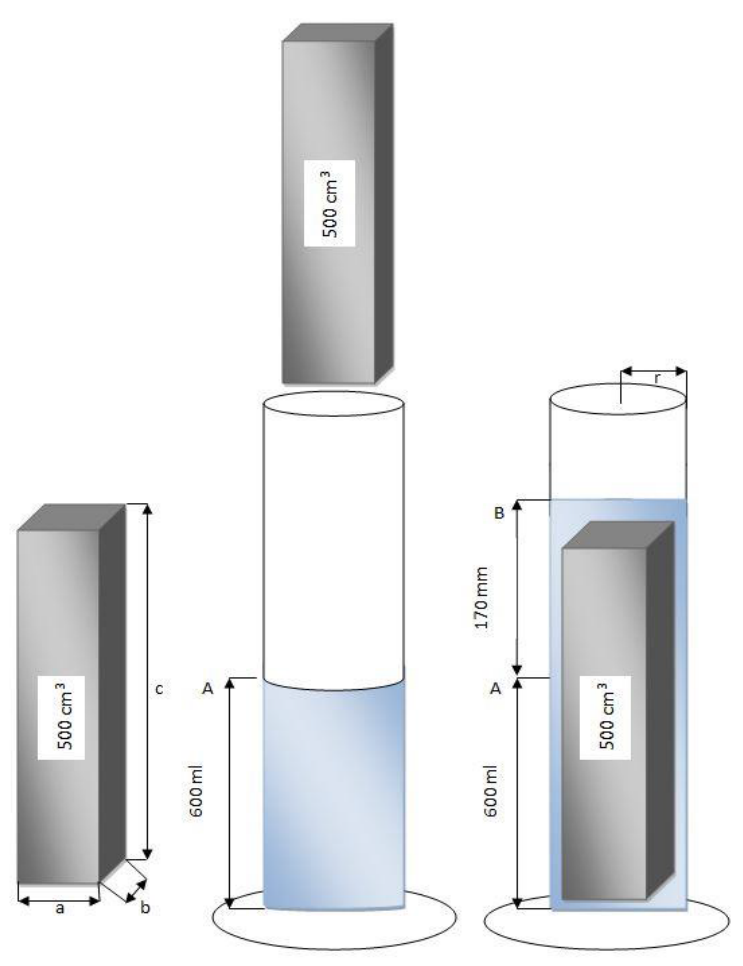

Figure 14: This figure represents the change in water levels from the mass. 
point where the aerometer no longer touches the base of the beaker. This means that gravity is zero (0) at the point where the aerometer rises from the base. We place the beaker in the scale in order to weigh it along with the water and the aerometer inside it, the weight is 1058.25 g. The weight of the beaker is subtracted from this value along with the weight of the aerometer in order to obtain the weight of the water. We remove the aerometer from the beaker. carefully and obtain the point $\mathrm{H}$ by adding water to the beaker in order to account for the removal of the aerometer, in which case the level of the water will fall. In order to continue with the calculation we need to first know the weight of the aerometer. In our case it is $\mathrm{h}=260.3 \mathrm{~mm}$. the weight of the water is $506.8 \mathrm{~g}$. The weight of the aerometer is $63.45 \mathrm{~g}$. the weight of the empty beaker is $488.70 \mathrm{~g}$.

Therefore we obtain:

$506.80 \mathrm{~g}+488.70 \mathrm{~g}+63.45 \mathrm{~g}=1058.25 \mathrm{~g}$.

Where: $\mathrm{r}=24.5 \mathrm{~mm} \Rightarrow \mathrm{r}^{2}=600.25$.

Calculations according to the formula: $\mathrm{V}=\mathrm{r}^{2} \cdot \pi \cdot \mathrm{h}$

$\mathrm{V}=600.25 \cdot 3.1415 \cdot 260.3 \mathrm{~mm}=490.84390 \mathrm{~mL}$.

Once the beaker is filled with $490.84390 \mathrm{ml}$ of water one will notice that the aerometer will sink to the base of the beaker. By calculating with the value $\pi=3.1415$ the volume of the beaker will be reduced and as a result the aerometer will sink. The gravity will not be subdued and the aerometer will sink to the base. If the calculation is done with the value 3.24 the volume of the beaker will not be reduced, and the result obtained will be correct and convincing.

In this calculation we break down the following formula: $\mathrm{V}=\mathrm{r}^{2}$. $3.24 \cdot h$.

$\mathrm{V}=600.25 \cdot 3.24 \cdot 260.3 \mathrm{~mm}=506.23404 \mathrm{~mL}$ this water weight is placed in the beaker and the aerometer is carefully placed inside the beaker. We will soon realize that the aerometer will not sink but will float near the base of the beaker. This ultimately suggests that the value 3.24 will not reduce the volume of the beaker and during the calculations will provide the exact weight of the water evident at the beginning of the experiment as shown in Figure 15A and 15B.

The diameter of the beaker and the weight of the aerometer in Figure $15 \mathrm{~A}$ and $15 \mathrm{~B}$ in the two calculations are equal. In the first calculation that is represented by Figure $15 \mathrm{~A}$, it is noticeable that the aerometer has sunk to the base of the beaker, this sunk is a result of calculating the volume of the beaker with the value $\pi=3.1415$. Having calculated the volume of the beaker with this value will result in a decreased beaker volume and as a result the sinking will follow, therefore the gravity is greater than the mass+volume of the aerometer and its water density. In Figure 15B when the volume of the beaker is calculated with the 3.24 value, the calculation will subdue the gravity and the aerometer will not sink to the base of the beaker.

\section{The Trigonometry of the Circle}

The circle with a center in the coordinate system with a radius is called a trigonometric circle. The length of the perimeter of a circle with $\mathrm{d}=100 \mathrm{~mm} \mathrm{r}=50 \mathrm{~mm}$ according to Archimedes $360^{\circ}$ is 314.15 $\mathrm{mm}$. consequently a quarter $(1 / 4)$ of the circle is $78.53 \mathrm{~mm}$. Therefore according to Archimedes (1/4) of $2 \pi$ is $78.53 \mathrm{~mm}$. This distance is also called a quadrant. A full circle has four quadrants. The distance of the perimeter of the circle from the point $\mathrm{E}$ to the point $\mathrm{H}$ which amounts to one-fourth $(1 / 4)$ of the circle, when we stretch it in a horizontal plane we will obtain point $\mathrm{A}$. in addition we obtain the point $\mathrm{B}$ when

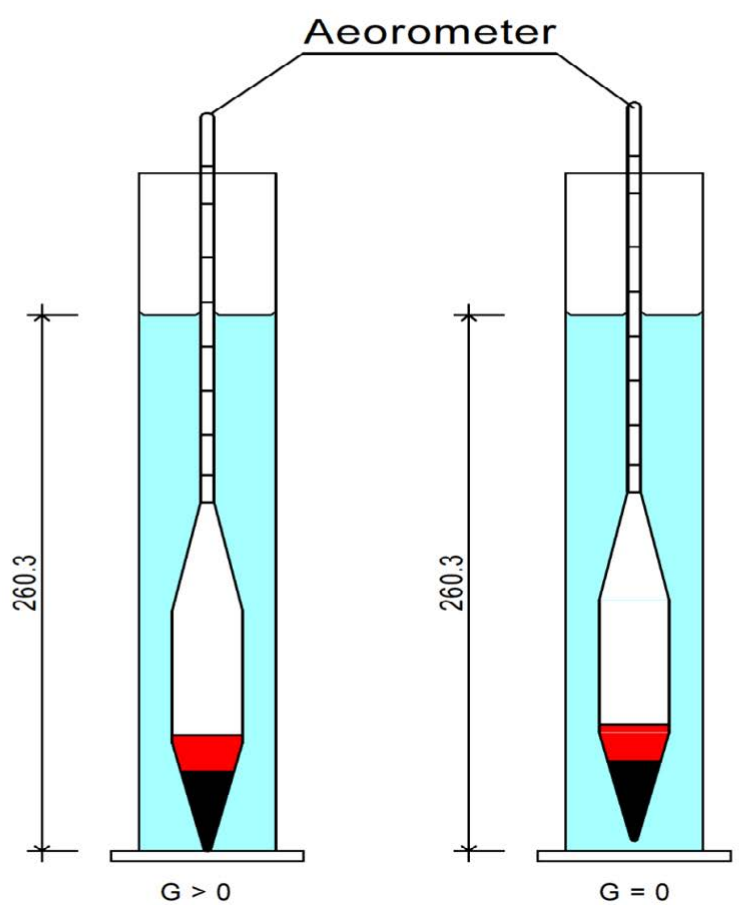

Figure 15: (A and $B$ ) The beaker filled with water, the aerometer is placed inside.

we extend the distance between points $\mathrm{E}$ and $\mathrm{F}$ in the horizontal plane. Then from the distance between points $\mathrm{G}$ and $\mathrm{H}$ we obtain the point $D$ and from the difference between points $G$ and $F$ we obtain the point F. From point A we draw a straight line passing through point $\mathrm{H}$. in which case we obtain point C. From point B we also draw a straight line which passes through the point $\mathrm{F}$ and meets point $\mathrm{C}$. From point $\mathrm{C}$ in the $y$-axis coordinate system. We measure the distance from point $\mathrm{C}$ to the center of the circle we understand that this distance is $88 \mathrm{~mm}$, a distance from which we understand nothing. The surface of the triangle from the center point $\mathrm{F}$ and point $\mathrm{C}$ is an area that has no meaning in relation to Figure 16 from this we understand that the length of 78.53 $\mathrm{mm}$ deviates the result of the circle's perimeter as well as its surface. While when the value of 3.24 is employed the length of the perimeter of the circle with $\mathrm{d}=100 \mathrm{~mm} \mathrm{r}=50 \mathrm{~mm} 360^{\circ}$ will be $324 \mathrm{~mm}$. When this length is divided into four parts we will have $81 \mathrm{~mm}$. therefore a quarter $(1 / 4)$ of the ring is $81 \mathrm{~mm}$. The perimeter distance from point $\mathrm{e}^{\prime}$ to point $\mathrm{h}$ ' is stretch in the horizontal plane we will obtain point $\mathrm{A}^{\prime}$. in addition we obtain the point $B$ when we extend the distance between points e' and $\mathrm{f}$ in the horizontal plane. then from the distance between points g' and h' we obtain the point $\mathrm{D}$ and from the difference between points $g$ ' and $f$ we obtain the point $F$. From point $A$ we draw a straight line passing through point $h^{\prime}$ in which case we obtain point $C$ in the $y$-axis. From point $B$ we also draw a straight line which passes through the point $f$ and meets point $c^{\prime}$. The distance from point $C^{\prime}$ to the center point of the circle in the $y$-axis is $81 \mathrm{~mm}$. The surface of the triangle from the center of the circle to the point $f$ and C' is $2025 \mathrm{~mm}^{2}$ when this value multiplied by four we will obtain the surface of the ring which is $8100 \mathrm{~mm}^{2}$. From this we understand that the circle with $\mathrm{d}=100 \mathrm{~mm}$ $360^{\circ}$ possesses $81 \mathrm{~cm}^{2}$ or $8100 \mathrm{~cm}^{2}$.

\section{$2025 \mathrm{~mm}^{2} \bullet 4=8100 \mathrm{~mm}^{2}$ ose $81 \mathrm{~cm}^{2}$.}

Conclusively, the circle with $\mathrm{d}=100 \mathrm{~mm}$ and $360^{\circ}$ its perimeter length is $324 \mathrm{~mm}$. and its surface is $81 \mathrm{~cm}^{2}$. 
Figure $15 \mathrm{~A}$ and $15 \mathrm{~B}$ will represent what the paragraph above explained.

$2025.00 \mathrm{~mm}^{2} \cdot 4=8100 \mathrm{~mm}^{2}=81 \mathrm{~cm}^{2}$.

Based on the trignomotery of the circle and the definition of the straight line we reach the conclusion that the value 3.1415 is a wrong one. In the text above and the Figures $16 \mathrm{~A}$ and $16 \mathrm{~B}$ above it is clearly explained that the value 3.1415 deviates the results with the value 3.24 provides the correct result.
The definition of the straight line is what prevents deviations in calculations. A straight line is a line that joints points A and B. along with all other points before point $A$ viewed from point $B$ and vice versa.

\section{The Radian Value}

From the center of the circle we draw a straight line to the circumference of the circle and obtain point A. From point A. we draw a vertical line of the same length. From the vertical position we extend the same length in the perimeter of the circle and obtain a point $B$,

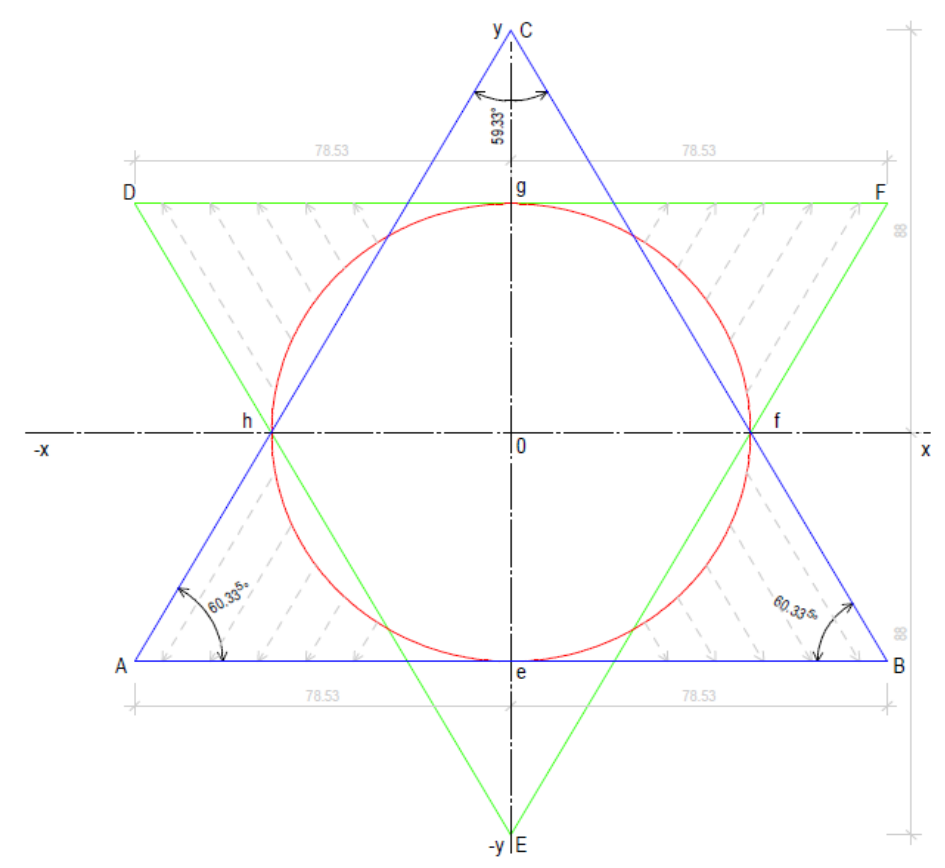

Figure 16A: The circle in the cordinate system, calculated with the value $\pi=3,141$ the length of the perimeter is $314,15 \mathrm{~mm}$, one fourth $(1 / 4)$ of the circle is $78,53 \mathrm{~mm}$

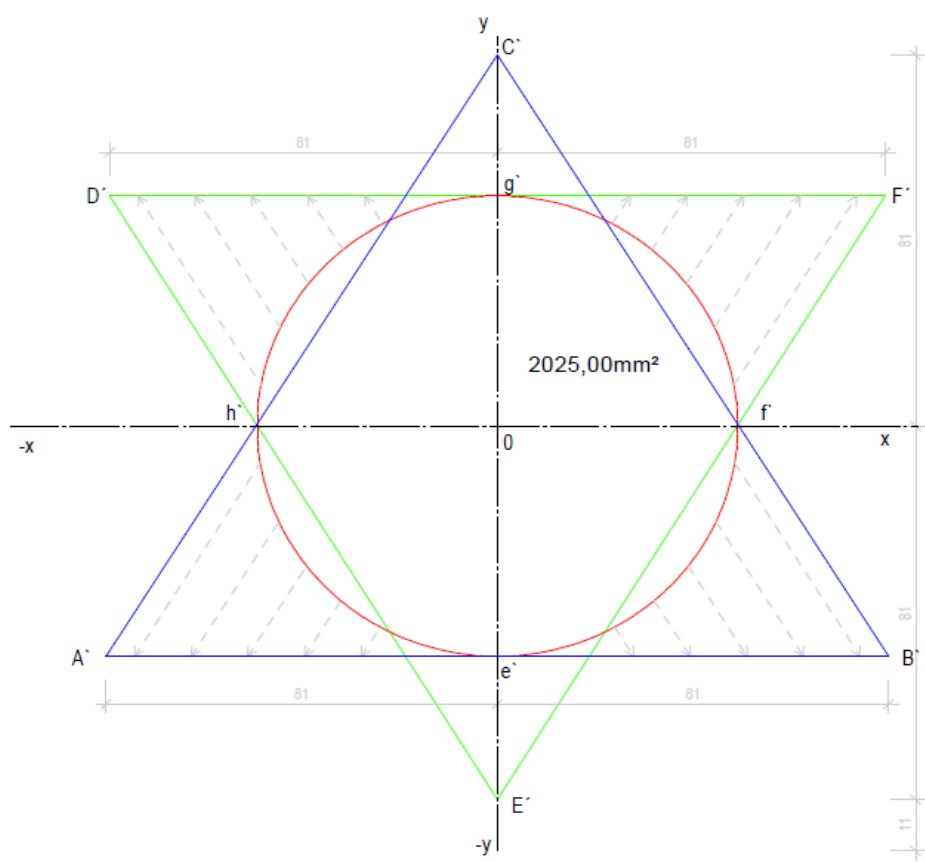

Figure 16B: The circle in the coordinate system, calculated with the value 3,24 the length of the perimeter is $324 \mathrm{~mm}$, one fourth $(1 / 4)$ of the circle is $81 \mathrm{~mm}$. 
Starting from point B we draw a straight line which touches the circle center at point $\mathrm{M}$ and thus we obtain an angle which is called a radian. The angle obtained is $1 \mathrm{rad}=55.55555556^{\circ}$ and the calculations that apply include the following:

$$
\begin{aligned}
& \text { 1 radian }=\frac{180}{3.24}=55.55555556^{\circ} \\
& 1_{\text {radian }}=\frac{180.60}{3.24}=3333.333^{\circ} \text { or } 1 \text { radian }=\frac{180.3600}{3.24}=200000.00^{\prime} \\
& \alpha=\frac{a}{b}=\text { rad } \\
& 1^{\circ}=\frac{6.48}{360^{\circ}}=0.018 \mathrm{rad}=>1^{\circ}=\frac{3.24}{180}=0.018 \text { radian } \\
& 1^{\circ}=60^{\prime}\left(\text { minuta) } 1^{\prime}=\frac{3.24}{180.60}=0.0003\right. \text { radian } \\
& 1^{\circ}=60 \bullet 60 \text { (sekonda) }=3600^{\prime \prime} \text { therefore } 1^{\prime \prime}=\frac{3.24}{180.3600}=0.000005 \text { radian. }
\end{aligned}
$$

Now it is clear how and where one can obtain the value of 0.018 radian.

\section{How and where can one obtain the recalculated value of the radian}

In a circle with $\mathrm{d}=100 \mathrm{~mm} \mathrm{r}=50 \mathrm{~mm}$ and $360^{\circ}$ the radian value is 6.48. This value is generally employed in different calculations (Figure 17). The radian value of 6.48 is equal to $360^{\circ}$ of the circle.

$\mathrm{r}=50 \mathrm{~mm}$

$50 \mathrm{~mm} \cdot 6=300 \mathrm{~mm}$

$300 \mathrm{~mm}+24 \mathrm{~mm}=324 \mathrm{~mm}$

$1^{\circ} \cdot \frac{24 \mathrm{~mm}}{0.9}=26.66666667^{\circ}$.

1 radian $=55.555556^{\circ} 360^{\circ}: 6.48=55.555556^{\circ}$.

$55.555556^{\circ} \bullet 6=333.3333334^{\circ}$

$0.48 \mathrm{rad}=26.6666667^{\circ}$

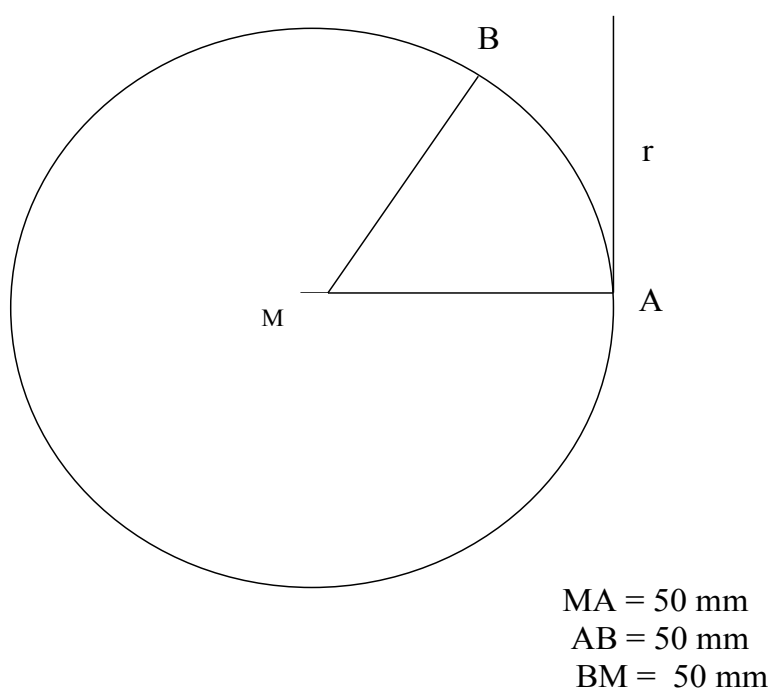

Figure 17: The manner in which the value of the radius can be obtained.

\section{$333.3333334^{\circ}+26.6666667^{\circ}=360.00^{\circ}$.}

From the calculation above one can understand how and where the radian value of 6.48 is obtained. When it comes to calculating the surface perimeter and angles the radian value of $6.48,0.9$ and 0.018 are extremely important values.

Below we have the representation of a circle with $\mathrm{d}=100 \mathrm{~mm} 360^{\circ}$ and 6.48 radian (Figure 18).

\section{Conclusion}

This paper addresses a number of issues, but in particular it provided answers to the following questions:

Why the value of $\mathrm{P}$ cannot be $\pi=3.1415$ ?

Why this value should be different?

Where can one notice these incorrect results and how much of an impact they have?

Based on the results obtained above it can be concluded that the value 3.1415 is a value that does not represent reality and does not give correct results. The reasons have been mentioned several times along with corresponding supporting arguments. For the sake of the truth this value should be different which will give an end to the series of errors. The consequences of employing the value above are great in any domain that this value is used.

The inconsistencies in the 3.1415 value were initially revealed in the geo-mechanical soil laboratory where this value always provides wrong results. Usually in these laboratories a number of tests are performed and the results obtained from these analyzes are forwarded further in order to be used for other more advanced calculations. The analyses which are conducted in the geo-mechanical soil laboratory include the following procedures: grain dispatch (size of the granules), sample cutting, compression, density, quantity, slope stability, deformations etc. These are tests which are directly impacted by the value 3.1415 . These tests are done in accordance to specific norms and standards and norms and are performed with adequate apparatuses. When analyzing direct cutting, where cohesion (c) and the tangent $(\varphi)$ are required. the

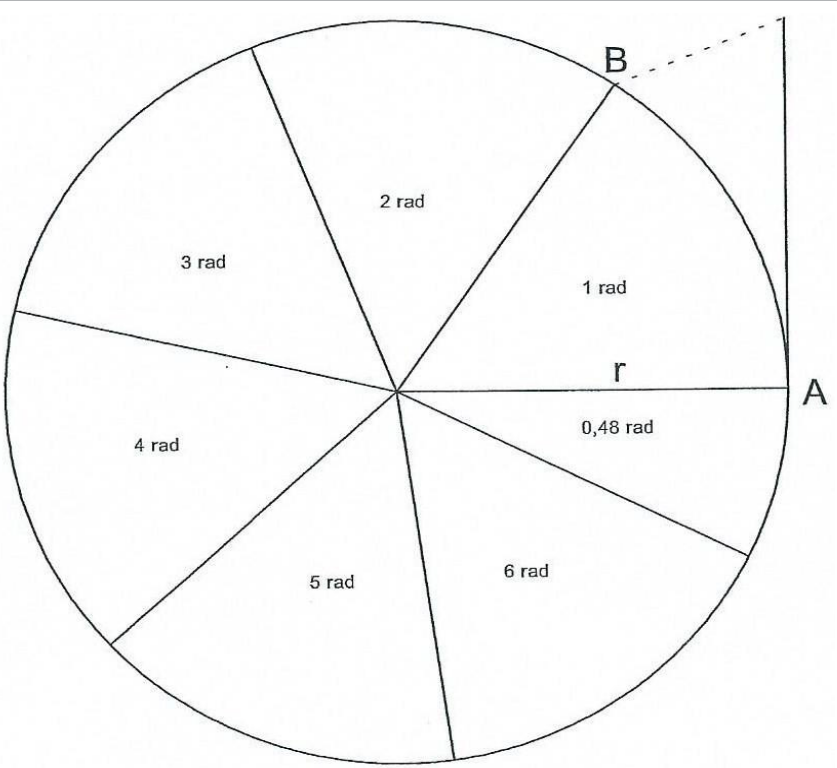

Figure 18: The circle with a radius $r=50 \mathrm{~mm}$, defined with the value of the circle. 
surface of the sample that enters the apparatus for analysis is of the size $\mathrm{d}=71 \mathrm{~mm} \mathrm{r}=35.5 \mathrm{~mm}$. When this surface is calculated according to Archimedes we obtain a smaller surface. The result is $39.57 \mathrm{~cm}^{2}$. While when this surface is calculated with the value $3.24 \mathrm{~cm}^{2}$ the result is $40.83 \mathrm{~cm}^{2}$. The real surface is bigger than the value obtained from the calculations which is why this calculation is providing incorrect results. The surface of $40.83 \mathrm{~cm}^{2}$ is calculated as $39.57 \mathrm{~cm}^{2}$. Consequently the tangent and cohesion are wrong results in this analysis. The next error takes place in compression analysis. Where in the frame of the apparatus we have a sample with the following specifications:

$\mathrm{d}=71 \mathrm{~mm} \mathrm{r}=35.05 \mathrm{~mm}$. this sample is compressed and the degree of its deformation is obtained. The main problem lies in the fact that the real sample in the frame of the apparatus is $40.83 \mathrm{~cm}^{2}$. While we calculate value of its surface is $39.57 \mathrm{~cm}^{2}$ which is lower due to the surface being calculated with the value $\pi=3.1415$.

From this we understand that the results are always wrong and we never obtain the correct result when measuring the surface. By breaking down the density formula where $\mathrm{D}=\mathrm{m} / \mathrm{v}$ the value $\pi=3.1415$ significantly deviates the results by decreasing the volume of the mass. While, the calculations which employ the 3.24 value during calculations of the mass volume obtain correct results, with the help of gravity it can also be concluded that the value of $\pi=3.1415$ deviates results for the volume. But gravity is the one who alerts the error and does not tolerate this deviation in results. While calculating with the value of 3.24 results are correct and the volume is not reduced. Quantity (water level) obtained with the volume and mass of the aerometer defeat gravity, the aerometer floats in the base of the beaker. The volume and the mass of the aerometer are the same in both calculations. In the proctor analysis, which is conducted to assess the density and moisture of the soil. We encounter the next mistake. This error occurs when the beaker in which the analysis is conducted the volume is calculated in the wrong way, because the value 3.1415 is employed and the result of the volume of the container are lower that they ought to be. Reviewing soil samples with the sample size $\varnothing 50 \mathrm{~mm}$ and length $100 \mathrm{~mm}$ which is subject to a vertical force exerted until its breaking point, provides results which are different from the ones that are visible in the frame of the apparatus. The reason is that the program used for calculations has the 3.1415 value programmed in its memory. Therefore, during calculations, the sample surface is reduced, the resisting strength of the sample is greater. The next mistake is evident in the analysis of granulate composition, conducted with the aerometer method. The aerometer is a working tool which should be calibrated and can be used for analysis only after it has been calibrated
The formula used to caliber the aerometer is the following:

$$
A=d^{2} \cdot \frac{\pi}{4}
$$

During the calculation of the calibration of the aerometer the value 3.1415 deviates the calibration outcome. The result obtained during the calibration is inserted in the program memory that is further used in calculating the distribution of the granules with the aerometer method and whenever this aerometer analysis is employed it will display incorrect results. This is uncomfortable with inconsistency and wondered why this is so. This paper will trigger debates among experts of the field in order to correct the mistakes of the past once and for all. The research results of the article are convincing and may lead to more arguments in the future in order to correct this mistake of the past which is costing humanity a great deal.

\section{References}

1. Li V, Müller F, Birner A, Nielsch K, Gösele U (1988) Hexagonal pore arrays with a 50-420 nm interpore distance formed by self-organization in anodic alumina. Journal of Applied Physics 84: 6023

2. Mochrie SGJ (1988) Four-circle angle calculations for surface diffraction. $J$ Appl Cryst 21: 1-4

3. Stanislav J, Mark TE (2008) On the Heegaard Floer homology of a surface times a circle. Advances in Mathematics 218: 728-761.

4. Vicente M, Wang BL (2005) Seiberg-Witten-Floer homology of a surface times a circle for non-torsion spin $\mathbb{C}$ structures. Mathematical news 278: 844-863.

5. Weltner K (1977) Mathematics for Physics Vieweg.

6. Samo Z, Prebil I (2001) Carrying angle and carrying capacity of a large single row ball bearing as a function of geometry parameters of the rolling contact and the supporting structure stiffness. Mechanism and Machine Theory 36: 1087-1103.

7. Ahmet $T$ (2006) Effect of flow geometry parameters on transient heat transfe for turbulent flow in a circular tube with baffle inserts. International Journal of Heat and Mass Transfer 49: 1559-1567.

8. Coxeter HSM (2003) The trigonometry of Escher's woodcut Circle Limit III. MC Escher's Legacy. Springer.

9. Graciela BS, Nomizu K (1984) Trigonometry in Lorentzian geometry. The American Mathematical Monthly 91: 543-549.

10. Margaret K, Stacey K (1996) Trigonometry: Comparing ratio and unit circle methods. Technology in Mathematics Education. Proceedings of the $19^{\text {th }}$ Annual Conference of the Mathematics education Research group of Australasia.

11. Honghai L (2017) Fuzzy qualitative trigonometry. Human Motion Sensing and Recognition. Springer. 